\section{Garlic in dermatology}

Nader Pazyar, Amir Feily

Jundishapur University of Medical Sciences, Department of Dermatology, Ahvaz, Iran

Abstract

Garlic (Allium sativum L. fam. Alliaceae) is one of the best-researched, best-selling herbal remedies and is also commonly used for treating various health problems. Garlic is widely known for its biological properties and plays an important role as an antioxidant. The purpose of this review is to gather and summarize all dermatologic-oriented in vitro and in-vivo experiments and clinical trials on garlic preparations. Extensive literatures search was carried out and twenty three studies were included. The results suggest that oral administration of garlic is effective on immunologic properties, cutaneous microcirculation, protection against UVB and cancer treatment. Additionally, topical application of garlic extract can potentially be effective on psoriasis, alopecia areata, keloid scar, wound healing, cutaneous corn, viral and fungal infection, leishmaniasis, skin aging and rejuvenation. Clinical effectiveness of oral and topical garlic extract is not sufficiently and meticulously explored as so far.

\section{Introduction}

Garlic (Allium sativum) is one of the bestresearched, best-selling herbal remedies and has been commonly used for treating various health problems for centuries. ${ }^{1}$ Garlic is a genus of some 500 species belonging to the family Liliaceae and Allium class of bulbshaped plants. ${ }^{2}$ Its constituents include enzymes (for example, alliinase), sulfur-containing compounds such as alliin, and compounds produced enzymatically from alliin (for example, allicin). ${ }^{2,3}$ Other constituents such as arginine, oligosaccharides, flavonoids, and selenium are available in garlic. ${ }^{2,3}$

Four garlic preparations including, raw garlic juice (RGJ), heated garlic juice (HGJ), dehydrated garlic powder (DGP) and aged garlic extract (AGE) are available. Different types of garlic preparations have different pharmacologic properties, and among the four garlic preparations, AGE is the most useful of them. ${ }^{4}$ Garlic extract is made from whole or sliced garlic cloves that are soaked in an alcohol solution for different amounts of time. ${ }^{5}$

\section{Ingredients}

Aged garlic extract (AGE) is a complex mixture. Its components include allin, cycloalliin, S-allyl-L-cysteine, S-methyl-L-cysteine, S-ethylcysteine, S-1-proponyl-L-cysteine, S-allylmercapto-L-cysteine, fructosyl-arginine, and betachlorogenin. It also consists of L-arginine, Lcysteine, and L-methionine. ${ }^{6}$

\section{Mechanism}

The compounds involved in the biological mechanisms such as flavenols, sulphur and seleno compounds have been identified. ${ }^{7}$ Garlic is also characterized by more polar compounds of phenolic and steroidal origin showing interesting pharmacological properties. ${ }^{8}$ Aged garlic extract stimulate immune functions such as proliferation of lymphocyte, cytokine release, NK activity and phagocytosis. ${ }^{9}$

\section{Adverse reactions}

Adverse reactions, related to garlic are potentially consist of irritant contact dermatitis, allergic contact dermatitis, protein contact dermatitis, zosteriform dermatitis,contact urticaria and induction of pemphigus. ${ }^{10}$ The purpose of this review is to gather and summarize all in vitro and in vivo and clinical trials on garlic preparations and their uses in dermatology.

\section{Dermatologic applications \\ of systemic garlic}

\section{Antioxidant effects}

Importantly, S-allylcysteine (SAC) and Sallylmercaptocysteine (SAMC) are the major organosulfur compounds in aged garlic extract which prevent oxidant damage. AGE exerts antioxidant action by scavenging reactive $0 x y$ gen species (ROS), enhancing the cellular antioxidant enzymes such as superoxide dismutase, catalase, glutathione peroxidase and increasing glutathione in the cells. AGE protects DNA against free radicals and defends against UV-induced damage. It also protects against some forms of UV-induced immunosuppression. ${ }^{11,12}$

\section{Cutaneous microcirculation}

A randomized placebo-controlled doubleblinded study show that $5 \mathrm{~h}$ after the administration of garlic powder a significant increase in capillary skin perfusion occurs by $55 \%$ in the healthy volunteers. The increased erythrocyte velocity results from vasodilation of precapillary arterioles which increases diameter of erythrocyte column by an average of $8.6 \% .^{13}$

\section{Immunomodulatory effect}

The major immunomodulatory proteins have been identified are known as garlic lectins. Aged garlic extract has more potent immunomodulatory effects than raw garlic. ${ }^{14}$
Correspondence: Amir Feily, Jundishapur University of Medical Sciences, Department of Dermatology, Ahvaz, Iran.

E-mail: dr.feily@yahoo.com

Key words: garlic, dermatology, review.

Conflict of interest: the authors report no conflicts of interest.

Received for publication: 29 March 2011.

Accepted for publication: 30 March 2011.

This work is licensed under a Creative Commons Attribution 3.0 License (by-nc 3.0).

(O)Copyright N. Pazyar and A. Feily et al., 2011

Licensee PAGEPress, Italy

Dermatology Reports 2011; 3:e4

doi:10.4081/dr.2011.e4

Garlic extract potentially induces the lymphocytes proliferation and macrophage phagocytosis, stimulates the infiltration of macrophages and lymphocytes in transplanted tumors, induces splenic hypertrophy, stimulates release of interleukin-2, tumor necrosis factoralpha and interferon-gamma and enhances natural killer cell and lymphokine-activated killer cell activity. These activities reflex effective stimulation of the immune response. ${ }^{15}$

\section{Anti cancer}

Two garlic-derived organosulfur compounds such as Se-methyl selenocysteine and gammaglutamyl-Se-methyl selenocysteine show anticancer activity. ${ }^{16}$ These include the effect on drug metabolizing enzymes, antioxidant properties, tumor growth inhibition, apoptosis, angiogenesis and increasing of natural killer (NK)cells. ${ }^{4,17}$ A molecular study displays that diallyl trisulfide (DATS) is a potential anticancer compound for skin cancer. ${ }^{18}$ Studies show that diallyl disulfide (DADS) induces caspasedependent apoptosis through a mitochondriamediated by intrinsic pathway in melanoma cells ${ }^{19}$ and appears to be a good candidate as an antitumor agent against melanoma. ${ }^{20}$

\section{UVB protection}

Garlic stimulates the proliferation of macrophages and lymphocytes and protects against the suppression of immunity by ultraviolet radiation. ${ }^{21}$ Aged garlic extract contains ingredients that protects from UVB-induced suppression of contact hypersensitivity and suggest that the mechanism of protection is by antagonism of the cis-urocanic acid mediation of this form of immunosuppression. ${ }^{22}$

\section{Dermatologic applications of topi- cal garlic extract}

\section{Psoriasis}

The activation of nuclear transcription fac- 
tor kappaB has now been linked with psoriasis. Extensive researches in the last few years have shown this pathway. This transcription factor can be interrupted by garlic (diallyl sulfide, $\mathrm{S}$ allylmercaptocysteine, ajoene). ${ }^{23}$

\section{Alopecia areata}

A double-blinded randomized controlled trial shows that the use of garlic gel significantly adds to the therapeutic efficacy of topical betamethasone valerate in alopecia areata and it can be an effective adjunctive topical therapy for alopecia areata. ${ }^{24}$

\section{Keloid scar}

Keloid scar is a chronic fibro-proliferative disease. It is hypothesized that garlic extract is able to inhibit nuclear factor-k B (NF-кB), nitric oxide (NO), matrix metalloproteinase (MMP)-2, Interleukin-6 (IL-6) and angiotensin converting enzyme (ACE); therefore, it can be potentially an effective treartment for keloid scar. $^{25}$

\section{Wound healing}

According to a study conducted by Bojs et al. contact allergy to garlic can be effective on wound healing. ${ }^{26}$ Investigation on chicken skin wounds exposed to aged garlic extract show an increase in the re-epithelialization and profuse dose-dependent neovascularization. ${ }^{27}$

\section{Viral infection}

Components of garlic have been shown to have antiviral effect and inhibit cellular proliferation of virally infected cells. One placebocontrolled trial demonstrates that the application of chloroform extracts of garlic result in the complete resolution of cutaneous warts without recurrence after 3-4 months. ${ }^{28}$

\section{Cutaneous corn}

A clinical trial reveals that the application of garlic extract on the cutaneous corns causes the complete removal of locations. The surrounding fibrin tissue of the corn capsule is lyzed and the capsule is separated from the main tissue .It seems due to the fibrinolytic effect of garlic extract. ${ }^{29}$

\section{Fungal infection}

According to a study diallyl sulphide (DAS) and diallyl disulphide (DADS) significantly inhibit proteinase, phospholipase secretion and dimorphism in candida albicans. These compounds can, therefore, act as a potent antifungal in the management of candidiasis. ${ }^{30} 0 \mathrm{n}$ the other hand, ajoene (allium-derived thiosulfinate compound) has been shown to be effective in short-term treatment of tinea pedis. One study shows the use of ajoene as a $0.4 \%$ (w/w) cream results in complete clinical cure of tinea pedis. Therefore, ajoene can be an alternative, efficient and low-cost antimycotic drug for short-term therapy of tinea pedis and superficial mycoses. The fact that ajoene can be easily prepared from an alcoholic extract of garlic may make it suitable for Third World public health care. ${ }^{31-33}$

\section{Leishmaniasis}

Treatment of leishmaniasis potentially relevant to Th1-type immune response. In vivo and in vitro studies demonstrate that garlic extract reduces footpad lesions in leishmania mexicana-infected BALB/c mice by inducing IFNgamma production from $\mathrm{T}$ cells as a Thl immunomodulator. In vitro, garlic extract reduce macrophage infection through induction of nitric oxide (NO) production. It may thus act on both $\mathrm{T}$ cells and macrophages to stimulate IFN-gamma production and NO synthesis for parasite killing. ${ }^{34}$ On contrary, a double blinded, placebo controlled study on 197 patients who received garlic cream $5 \%$ or placebo demonstrated it is not effective treatment for cutaneous leishmaniasis. ${ }^{35}$

\section{Anti-aging}

According to an investigation garlic shows beneficial effects on the maximum proliferative capacity of fibroblasts on long-term, therefore, garlic can play a role as an anti-aging and rejuvenative agent. ${ }^{36}$

\section{Conclusions}

Garlic extract can inhibit photocarcinogenesis and garlic extract -containing sunscrens may be valuable in Australasian countries and in cancer-provoking conditions, such as Gorlin's syndrome and xeroderma pigmentosum. Additionally, it can be effective on maximum proliferative capacity on fibroblasts and garlic extract -containing creams may be of particular value in preventing of skin aging and as a novel addition to rejuvenation. On the other hand, garlic extract has been reported as a Th1 immunomodulator and the pathogenesis of psoriasis is relevant to Th1, therefore, it maybe effective on psoriasis in combination with topical steroid and emollient as a new addition to psoriasis therapy.

\section{References}

1. Yilmaz HH, Gormez 0, Hastar E, et al. Garlic burn in a patient with trigeminal neuralgia: a case report Eur J Dent 2010; 4:88-90.

2. Cultivation Garlic. Available at: http:// htysite.co.tv/budidaya\%20bawang\%20puti h\%20ig.htm Accessed march/23/2011

3. Aviello G, Abenavoli L, Borrelli F, et al. Garlic: empiricism or science? Nat Prod
Commun 2009;4:178517-96.

4. Kasuga S, Uda N, Kyo E, et al. Pharmacologic activities of aged garlic extract in comparison with other garlic preparations. J Nutr 2001;131:1080S-4S.

5. Amagase $\mathrm{H}$. Clarifying the real bioactive constituents of garlic. J Nutr 2006;136: 716S-725S.

6. Allison GL, Lowe GM, Rahman K. Aged garlic extract and its constituents inhibit platelet aggregation through multiple mechanisms. J Nutr 2006;136:782S-788S.

7. Arnault I, Auger J. Seleno-compounds in garlic and onion. J Chromatogr A 2006; 1112:23-30.

8. Lanzotti V. The analysis of onion and garlic. J Chromatogr A 2006;1112:3-22.

9. Sumiyoshi H. New pharmacological activities of garlic and its constituents. Nippon Yakurigaku Zasshi 1997;1101:93P-7P.

10. Jappe U, Bonnekoh B, Hausen BM, Gollnick H. Garlic-related dermatoses: case report and review of the literature. Am J Contact Dermat 1999;10:37-9.

11. Borek C. Antioxidant health effects of aged garlic extract. J Nutr 2001;131:1010S-5S.

12. Imai J, Ide $\mathrm{N}$, Nagae $\mathrm{S}$, et al. Antioxidant and radical scavenging effects of aged garlic extract and its constituents. Planta Med 1994;60:417-20.

13. Jung EM, Jung F, Mrowietz C, et al. Influence of garlic powder on cutaneous microcirculation. A randomized placebocontrolled double-blind cross-over study in apparently healthy subjects. Arzneimittelforschung 1991;41:626-30.

14. Chandrashekar PM, Venkatesh YP. Identification of the protein components displaying immunomodulatory activity in aged garlic extract. J Ethnopharmacol 2009;124:384-90.

15. Lamm DL, Riggs DR. Enhanced immunocompetence by garlic: role in bladder cancer and other malignancies. J Nutr 2001; 131:1067S-70S.

16. Arnault I, Auger J. Seleno-compounds in garlic and onion. J Chromatogr A 2006; 1112:23-30.

17. Milner JA. Preclinical perspectives on garlic and cancer. J Nutr 2006;136:827S-31S.

18. Wang HC, Yang JH, Hsieh SC, Sheen LY. Allyl sulfides inhibit cell growth of skin cancer cells through induction of DNA damage mediated G2/M arrest and apoptosis. J Agric Food Chem 2010;58:7096-103.

19. Pratheeshkumar P, Thejass P, Kutan G. Diallyl disulfide induces caspase-dependent apoptosis via mitochondria-mediated intrinsic pathway in B16F-10 melanoma cells by up-regulating p53, caspase- 3 and down-regulating pro-inflammatory cytokines and nuclear factor- $\kappa \beta$-mediated Bcl-2 activation. J Environ Pathol Toxicol Oncol 2010;29:113-25. 
20. Hakimzadeh H, Ghazanfari T, Rahmati B, Naderimanesh H. Cytotoxic effect of garlic extract and its fractions on Sk-mel3 melanoma cell line. Immunopharmacol Immunotoxicol 2010;32:371-5.

21. Lamm DL, Riggs DR. The potential application of Allium sativum (garlic) for the treatment of bladder cancer. Urol Clin North Am 2000;27:157-62.

22. Reeve VE, Bosnic M, Rozinova E, BoehmWilcox C. A garlic extract protects from ultraviolet B $(280-320 \mathrm{~nm})$ radiationinduced suppression of contact hypersensitivity. Photochem Photobiol 1993;58:8137.

23. Aggarwal BB, Shishodia S. Suppression of the nuclear factor-kappaB activation pathway by spice-derived phytochemicals: reasoning for seasoning. Ann N Y Acad Sci 2004;1030:434-41.

24. Hajheydari Z, Jamshidi M, Akbari J, Mohammadpour R. Combination of topical garlic gel and betamethasone valerate cream in the treatment of localized alopecia areata: a double-blind randomized controlled study. Indian J Dermatol Venereol Leprol 2007;73:29-32.
25. Feily A, Namazi MR, Pazyar N, et al. Garlic extract as a novel addition to antikeloid armamentarium: an untested hypothesis. J Altern Complement Med 2009;15:1153-4.

26.Bojs G, Svensson A. Contact allergy to garlic used for wound healing. Contact Dermatitis 1988;18:179-81.

27. Ejaz S, Chekarova I, Cho JW, et al. Effect of aged garlic extract on wound healing: a new frontier in wound management. Drug Chem Toxicol 2009;32:191-203.

28. Lipke MM. An armamentarium of wart treatments. Clin Med Res 2006;4:273-93.

29. Dehghani F, Merat A, Panjehshahin, Handjani F. Healing effect of garlic extract on warts and corns. Int J Dermatol 2005; 44:612-5.

30. Yousuf S, Ahmad A, Khan A, et al. Effect of garlic-derived allyl sulphides on morphogenesis and hydrolytic enzyme secretion in Candida albicans. Med Mycol 2010 Dec 3. [Epub ahead of print]

31. Ledezma E, López JC, Marin P, Romero H, et al. Ajoene in the topical short-term treatment of tinea cruris and tinea corporis in humans. Randomized comparative study with terbinafine. Arzneimittel- forschung 1999;49:544-7.

32. Ledezma E, Marcano K, Jorquera A, et al. Efficacy of ajoene in the treatment of tinea pedis: a double-blind and comparative study with terbinafine. J Am Acad Dermatol 2000;43:829-32.

33. Ledezma E, DeSousa L, Jorquera A, et al. Efficacy of ajoene, an organosulphur derived from garlic, in the short-term therapy of tinea pedis. Mycoses 1996;39:393-5.

34. Gamboa-León MR, Aranda-González I, Mut-Martín M, et al. In vivo and in vitro control of Leishmania mexicana due to garlic-induced NO production. Scand J Immunol 2007;66:508-14.

35. Gholami AR, Khamesipour A, Momeni A, et al. Treatment of cutaneous leishmaniasis with 5\% garlic cream: A randomized, double-blind study. Iran J Derm 2000;3:2-6.

36. Svendsen L, Rattan SI, Clark BF. Testing garlic for possible anti-ageing effects on long-term growth characteristics, morphology and macromolecular synthesis of human fibroblasts in culture. J Ethnopharmacol 1994;43:125-33. 